\title{
ASSESSMENT OF VON WILLEBRAND FACTOR AND SOLUBLE FIBRIN MONOMER COMPLEX IN LEUKEMIC PATIENTS
}

\author{
By \\ Mohammed Abd El-Moaty Ebraheem Shaheen*, Nagwa Mohammed \\ Mowafy* and Abd El-Rauf Abd El-Rauf Abo-Nar* \\ Department of Clinical Pathology*, Al-Azhar Faculty of Medicine \\ E-mail: docshaheen90@gmail.com, E-mail: mowafy_n96@yahoo.com
}

\begin{abstract}
Background: Acute myeloid leukemia (AML) is a common hematological malignancy characterized by the clonal growth of myeloblasts/promyelocytes not only in the bone marrow but also in peripheral blood and/or tissues. Thrombosis is a major complication; early detection of thrombotic event is the important of its treatment. Von Willebrand factor (VWF) is a major component of hemostasis. Soluble fibrin monomer complex (SFMC) forms in early stage of thrombus formation by fusion of two fibrinogen molecules and one fibrin monomer.

Objective: To assess the levels of VWF Ag, a disintegrin and metalloproteinase with a thrombospondin type I motif, member13 (ADAMTS13), D dimer \& SFMC in patients with AML.

Patients and methods: The study was conducted on 40 patients newly diagnosed as AML patients. They were compared with 40 healthy individuals with identical demographic characteristics not suffering from any disease. Levels of VWF Ag, ADAMTS13, D dimer and SFMC were measured in both groups by enzyme linked immunosorbent assay (ELISA).This study carried out over a period from April2019 and March 2020, at Sayed Galal University Hospital.
\end{abstract}

Results: A significant increase in VWF Ag, SFMC, DD and a significant decrease in ADAMTS13 level occurred in all patients with AML compared with control group. ( $\mathrm{p}=<0.0001)$.

Conclusion: VWF and ADAMTS13 played an important role in hypercoagulability state in AML patients. SFMC could be used as an early indicator of hypercoagulability.

Keywords: VWF Ag, SFMC, SFMC, D dimer, AML.

\section{INTRODUCTION}

Acute leukemia (AL) is a progressive malignant neoplasm of hematopoietic stem cells with acute onset, severe symptoms, poor survival rates, and frequent recurrence compared with solid tumors (Wang et al., 2020).

Acute myeloid leukemia (AML) is an extremely heterogeneous disease defined by the clonal growth of myeloblasts/promyelocytes not only in the bone marrow but also in peripheral blood and/or tissues (Kirtonia et al., 2020).

Thrombotic events are a major cause of morbidity and mortality in cancer. While theassociation of venous thromboembolic events with cancer is well documented, in recent years, arterial events (i.e. acute myocardial infarction and ischemic strokes) have also emerged as relatively common complications among cancer patients. In hematological malignancies, 
the prediction of thrombosis occurrence and/or recurrence is challenging, due to unique disease characteristics (Horowitz and Brenner, 2020).

Fibrinogen is a soluble macromolecule, but forms an insoluble clot or gel on conversion to fibrin by the action of the serine protease thrombin, which is activated by a cascade of enzymatic reactions triggered by vessel wall injury, activated blood cells, or a foreign surface (Weisel and Litvinov, 2017).

Soluble fibrin monomer complex (SFMC) appears in the bloodstream during the extremely early stage of blood coagulation. Thrombin cleaves fibrinopeptides from a fibrinogen molecule, and yields a fibrin monomer. When fibrin monomers are produced in the presence of fibrinogens, two fibrinogen molecules and one fibrin monomer create a soluble complex known as SFMC. SFMC reflects the plasmatic activation of coagulation and fibrinolysis (Kochi et al., 2017).

Von Willebrand factor (VWF) (a major component of hemostatic system) was discovered to play an important role in the pathogenesis of thrombosis in various clinical situations (Wu et al., 2020).

It is ultralarge VWF (ULVWF) that produces a marked effect in recruiting circulating platelets to the site of endothelial activation and injury. But ULVWF is not usually found in the circulation. Indeed, a metalloprotease called a disintegrin and a metalloproteinase with a thrombospondin type I motif, member 13 (ADAMTS13), cleaves ULVWF into smaller, less active multimers (Khan et al., 2012).
An association between high VWF levels and thrombosis has frequently been reported, and more recently also an association has been observed between low ADAMTS13 levels and arterial thrombosis (Mohren et al., 2016).

This study was performed to assess the levels of VWF, ADAMTS13, D dimer \& SFMC in patients with AML.

\section{SUBJECTS AND METHODS}

The study included 40 patients, and 40 healthy controls. This study carried out over a period from April2019 and March 2020, at Sayed Galal University Hospital. Patients were classified into 2 groups:

Group I (M3): Eleven patients had AMLM3, 7 males and 4 females, their ages ranged between 41 and 66 years.

Group II (Non-M3): Twenty-nine patients had non-M3 AML. 16 males and 13 females, their ages ranged from 37 to 72 years.

Control group: Forty apparently healthy controls with oral consent, 24 males and 16 females, their ages ranged from 41 to 61 years.

Inclusion criteria: Any patient diagnosed for the first time as an AML patient was included in our research (after revision of their flowcytometry results).

Exclusion criteria: Any patient with recurrent AML or started treatment for AML or thrombosis, was excluded from our research.

\section{All patients and control group were subjected to the following:}

I. Full history and clinical examination.

II. Peripheral blood samples $(4 \mathrm{~mL}$ on two $3.2 \%$ citrate vacutainer, one for VWF 
Ag and ADAMTS13, the other for DD and SFMC).

\section{Samples were submitted to the following:}

1. Assessment of VWF Ag (ELISA).

2. Assessment of ADAMTS13 (ELISA).

3. Assessment of SFMC (ELISA).

4. Assessment of DD (ELISA).

Basic principles of enzyme-linked immunosorbent assay (ELISA) study:

The principle was the same for the four analytes (VWF Ag, ADAMTS13, DD and SFMC).

The used assay was a sandwich ELISA. The capture antibody specific for analyte was immobilized to 96-microwell polystyrene plates. Patient plasma was incubated in the wells, allowing any available analyte to bind to the antianalyte antibody to the plastic. The plates were rinsed to remove any unbound plasma analytes. Bound analyte was quantitated using a conjugate (horseradish peroxidase (HRP) conjugated anti-analyte detection antibody). Any unbound conjugated antibody was washed away after an incubation period. A chromogenic substrate of tetramethylbenzidine (TMB) and hydrogen peroxide ( $\mathrm{H} 2 \mathrm{O} 2)$ was added to develop a colored reaction. The intensity of the color was measured spectrophotometrically at $450 \mathrm{~nm}$ in O D units. Concentrations of the analyte were determined against a curve made from reference plasma provided.

Samples and kit reagents were brought to room temperature $\left(15-30^{\circ} \mathrm{C}\right)$ and mixed well before using:
1. The $1^{\text {st }}$ well (A1) was kept for blank. All reagent components were put without sample. It was used to zero the plate reader.

2. The next 7 wells (From B1 to H1) were used for standard curve preparation.

3. $100 \mu \mathrm{L}$ (in VWF Ag and DD) or 50 (in ADAMTS13 and SFMC) of diluted reference plasma, positive and negative control, samples were added to the appropriate micro wells.

4. Plates are covered and incubated for 1 $\mathrm{hr}$ at $37^{\circ} \mathrm{C}$ (in VWF Ag and DD) or 15$30 \mathrm{~min}$. at $15-30^{\circ} \mathrm{C}$ (in ADAMTS 13 and SFMC).

5. After the incubation was complete, microwells were carefully inverted to decant the sample fluid. Care was taken to prevent sample from one microwell to flow into another.

6. Washing was done 4 times. Each well was filled with wash solution per wash. Micro wells were inverted between each wash to empty fluid. A snapping motion of the wrist was done to shake the liquid from the wells. Plates were blotted on absorbent paper to remove residual wash fluid. Care was taken to guard against drying out of micro wells between steps.

7. After washing was complete, $100 \mu \mathrm{L}$ (in VWF $\mathrm{Ag}$ and DD) or 50 (in ADAMTS13 and SFMC) of conjugate solution were added to wells.

8. Incubation and washing were done as descried in steps $4,5,6$.

9. $100 \mu \mathrm{L}$ (in VWF Ag and DD) or 50 (in ADAMTS13 and SFMC) of substrate were added to wells. 
10. Incubation was performed as described before but in dark and at room temperature.

11. Stopping solution - $100 \mu \mathrm{L}$ (in VWF $\mathrm{Ag}$ and $\mathrm{DD}$ ) or 50 (in ADAMTS13 and SFMC) - were added to wells.

12. O.D. values were measured immediately after the addition of Stopping Solution. Reading was done by Chromate plate reader using Chromate manager software.

13. Standard curves were done using Microsoft excel 2016.
14. The equation of the trend line (e.g.: VWF Ag trend line equation: $\mathrm{Y}=$ $0.0123 \mathrm{X}+0.0679)$ was used by Microsoft excel 2016 to calculate concentrations from OD measured by the plate reader.

\section{Statistical analysis:}

Data were analyzed using Statistical Package for the Social Sciences (SPSS) version 2, IBM Corp. U.S.A.

Mann-Whitney $\mathbf{U}$ test was used to compare between two medians. P-value $<0.05$ was considered significant.

\section{RESULTS}

Our study showed a highly statistical significant difference (P-value: <0.001) between patients and control regarding VWF Ag. Also, we showed a statistical significant difference (P-value: <0.001) between patients and control regarding ADAMTS 13. A statistical significant difference (P-value: <0.001) was between patients and control regarding SFMC and D Dimer (Table 1).

Table (1): Comparison between patients and control regarding VWF Ag, ADAMTS 13, D dimer and SFMC

\begin{tabular}{|c|c|c|c|c|c|c|}
\hline \multirow{2}{*}{ Parameters } & \multicolumn{2}{|c|}{ Patients $(\mathrm{N}=\mathbf{4 0})$} & \multicolumn{2}{|c|}{ Control $(\mathrm{N}=40)$} & \multirow{2}{*}{$\begin{array}{c}\text { MW (Mann } \\
\text { Whitney U } \\
\text { test) }\end{array}$} & \multirow[b]{2}{*}{ P-value } \\
\hline & Median & IQR & Median & IQR & & \\
\hline VWF Ag & 254.8 & 194-332 & 115.9 & 94.8-132.8 & 137 & $<0.001$ \\
\hline ADAMTS 13 & 45.3 & 21.8-70.8 & 99.6 & 82.2-119.4 & 159 & $<0.001$ \\
\hline D dimer & 1.3 & $0.7-2$ & 0.10 & 0-0.17 & 168 & $<0.001$ \\
\hline SFMC & 8.9 & $5.7-14.4$ & 3.6 & 2.1-4.4 & 288 & $<0.001$ \\
\hline
\end{tabular}

\section{DISCUSSION}

VWF Ag increased in patient group compared with control group. Such results were concordant with that of Zhang et al. (2014) who reported that VWF Ag \% was increased in patients with AML compared with control group. Also, our results were concordant with that of El Sherif et al. (2014) who reported that VWF Ag \% increase in patients with ALL compared with control group.

Sacco et al. (2020) reported similar results in patients with polycythemia vera.Similar results in Waldenstrom macroglobulinemia (WM) were reported by Gavriatopoulou et al. (2019) who reported that VWF $\mathrm{Ag} \%$ increase in 
patients with WM compared with control group.

Our study also showed that VWF Ag increased but statistically insignificant in patients with M3 AML compared with non-M3 patients, which may contribute to the pathogenesis of hypercoagulability in M3 patients.

Also, we revealed that VWF Ag was positively correlated with TLC, negatively correlated with $\mathrm{Hb}$ and platelets. Thus: the levels regarding ADAMTS 13. A statistical significant difference (P-value: $<0.001)$ was between patients and control regarding SFMC and D Dimer (Table 1) may point to the extent of the disease.

Also, VWF Ag negatively correlated with ADAMTS13, positively correlated with SFMC and DD.ADAMTS13 decreased in patient group compared with control group.

Our results were concordant with that of Zhang et al. (2014) who reported that ADAMTS13 \% decreased in patients with AML compared with control group. Gavriatopoulou et al. (2019) reported similar results in patients with WM.

However, on contrary to our study, Sacco et al. (2020) reported that ADAMTS13 levels were similar between patients with PV and healthy subjects.

Sun et al. (2016) studied ADAMTS13 activity in a wide range of patients (atherosclerosis, diabetes, acute promyelocytic leukemia, cancer and sepsis), and found that ADAMTS13 activity significantly decreased compared with healthy control.

Our study also revealed that ADAMTS13 decreased (statistically insignificant) in M3 AML patients compared to non-M3 AML patients. A study of a larger number of patients may give significant difference. So, M3 AML patients are prone to hypercoagulability more than non-M3 AML patients.

ADAMTS13 negatively correlated with VWF Ag. D dimer increased in patient group compared with control group.

Our results were concordant with that of Shenoy et al. (2014) who reported that $\mathrm{d}$ dimer elevated in an acute leukemia patient. Geng et al. (2016) studied the prognostic value of d-dimer in de novo acute myeloid leukemia. They reported that D-dimer was related to high tumor burden and can be considered as an independent prognostic factor in patients with de novo non-M3 AML. We also found that DD increased in M3 AML patients compared to non-M3 AML patients, who denote the process of thrombus formation and degeneration (fibrinolysis).

DD was positively correlated with SFMC, VWF $\mathrm{Ag}$ and negatively correlated with ADAMTS13. SFMC increased in patient group compared with control group.

We could not find previous related studies of SFMC in AML or even in AL. our study was the first to discuss that analyzes SFMC in AML.

Our study also revealed that SFMC increased in M3 AML patients compared to non-M3 AML patients.

This was an early evidence of hypercoagulability in M3 AML patients. We also studied the relation between SFMC and other parameters. SFMC was 


\section{MOHAMMED A. E. SHAHEEN et al.,}

positively correlated with DD and VWF Ag. SFMC was negatively correlated with ADMATS13.

Thus, being positively correlated with DD, SFMC could be an early indicator of hypercoagulability in AML patients.

\section{CONCLUSION}

- VWF level increased in patients with AML, specially M3-AML, which may play a role in the pathogenesis of hypercoagulability.

- Being positively correlated with DD, SFMC, and negatively correlated with ADAMTS13, patients with higher level of VWF Ag should be given a special attention for the occurrence of thrombosis.

- ADAMTS13 decreased in AML patients, specially M3-AML, thus, contributing to hypercoagulability by allowing the level of HMWM of VWF to increase.

- DD increased in AML patients, specially M3-AML.

- SFMC increased in AML patients, specially M3-AML.

- SFMC positively correlated with DD, it could be used as an early marker of hypercoagulability.

\section{ACKNOWLEDGEMENT}

We would like to thank the Clinical Pathology Department of Al-Azhar Faculty of Medicine. We also indebted to all the patients and our colleagues for their co-operation in this research.

\section{REFERENCES}

1. El Sherif, N. H., Narouz, M. F., Elkerdany, T. A. and El Habashy, S. A. (2014): Von Willebrand factor and factor VIII levels in
Egyptian children with newly diagnosed acute lymphoblastic leukemia in relation to peripheral blast cells and steroid therapy. Journal of Pediatric Hematology Oncology, 36(7): 518-523.

2. Gavriatopoulou, M., Terpos, E., NtanasisStathopoulos, I., Papasotiriou, I., Fotiou, D., Migkou, M., ... and Dimopoulos, M. A. (2019): Elevated vWF Antigen Serum Levels Are Associated With Poor Prognosis, and Decreased Circulating ADAMTS-13 Antigen Levels Are Associated With Increased IgM Levels and Features of WM but not Increased vWF Levels in Patients With Symptomatic WM. Clinical Lymphoma Myeloma and Leukemia, 19(1): 23-28.

3. Geng, Y., Jian, C., Yang, S., Wu, S., Zhou, J., and Li, D. (2016): The prognostic value of d-dimer in de novo acute myeloid leukemia. The American Journal of the Medical Sciences, 352(2): 129-133.

4. Horowitz, N. A. and Brenner, B. (2020): Thrombosis in hematological malignancies: mechanisms and implications. Thrombosis Research, 19(1): S58-S62.

5. Khan MM, Motto DG, Lentz SR and Chauhan AK. (2012): ADAMTS13 reduces VWF-mediated acute inflammation following focal cerebral ischemia in mice. J Thromb Haemost., 10(8):1665-1671.

6. Kirtonia, A., Pandya, G., Sethi, G., Pandey, A. K., Das, B. C. and Garg, M. (2020): A comprehensive review of genetic alterations and molecular targeted therapies for the implementation of personalized medicine in acute myeloid leukemia. Journal of Molecular Medicine, 9(8): 1069-1091

7. Kochi, M., Shimomura, M., Hinoi, T., Egi, H., Tanabe, K., Ishizaki, Y., Adachi, T., Tashiro, H. and Ohdan, H. (2017): possible role of soluble fibrin monomer complex after gastroenterological surgery. World Journal of Gastroenterology, 23(12): 2209.

8. Mohren, M., Jentsch-Ullrich, K., Koenigsmann, M., Kropf, S., Schalk, E. and Lutze, G. (2016): High coagulation factor VIII and von Willebrand factor in patients with lymphoma and leukemia. 
International Journal of Hematology, 103(2): 189-195.

9. Sacco, M., Ranalli, P., Lancellotti, S., Petrucci, G., Dragani, A., Rocca, B. and De Cristofaro, R. (2020): Increased von Willebrand factor levels in polycythemia vera and phenotypic differences with essential thrombocythemia. Research and Practice in Thrombosis and Haemostasis, 4(3): 413-421.

10. Sun, C. F., Liu, G. Q., Zhao, X., Han, F., Xu, M., Xing, J. and Liu, J. (2016): ADAMTS13 Level in Prothrombotic Status and Its Related Factor Analysis. Zhongguo shi yan xue ye xue za zhi, 24(4): 1125-1131.

11. Wang, C., Yan, J., Chen, J., Wang, Y., Lin, Y. C., Hu, R. and Wu, Y. (2020): Factors associated with quality of life of adult patients with acute leukemia and their family caregivers in China: a cross-sectional study.
Health and Quality of Life Outcomes, 18(1): $1-9$.

12. Weisel, J. W., and Litvinov, R. I. (2017): Fibrin Formation, Structure and Properties. Sub-Cellular Biochemistry, 8(2): 405-456.

13. Wu, W. T., Zhussupbekov, M., Aubry, N., Antaki, J. F. and Massoudi, M. (2020): Simulation of thrombosis in a stenotic microchannel: The effects of vWF-enhanced shear activation of platelets. International Journal of Engineering Science, 14(7): 103206.

14. Zhang, W. J., Han, Y., Ma, Z. N., Wang, Q., Tang, Y. Q., Wang, J., ... and Wu, D. P. (2014): Changes of adamts 13 activity and VWF antigen level in patients with acute myelogenous leukemia and their significance. Zhongguo shi yan xue ye xue za zhi, 22(6): 1503-1507. 
تقييم عامل فونويليبر اندو مركب الفيبرين الأحادي القابل



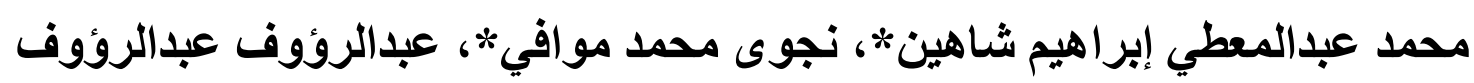
* أبونار

\section{قسم الباثولوجيا الاكلينيكية، كلية الطب، جامعة الازهر}

E-mail: $\underline{\text { docshaheen90@gmail.com, E-mail: mowafy_n96@yahoo.com }}$

خلفية البحث: ينتشر سرطان الدم في جميع البلدان والأعمار . ومنه سرطان الدم النخاعي الحاد الذي

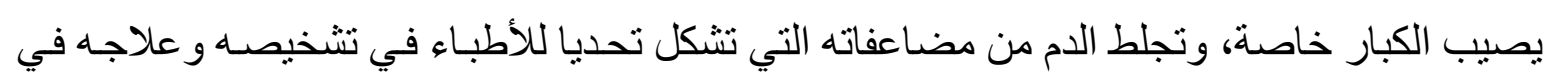

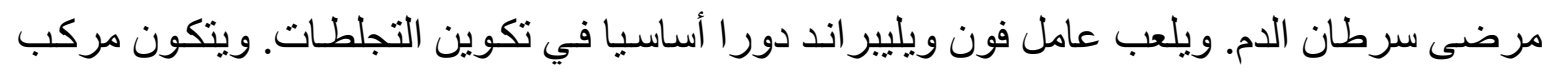

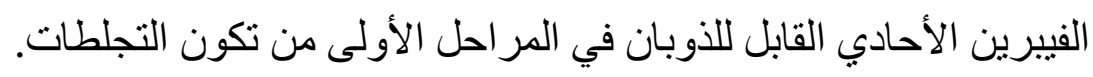

الههف من البحث: تقييم مستوى عامل فون ويليير اند و إنزيم الأدمتس 13 ومركب الفيبرين الأحادي

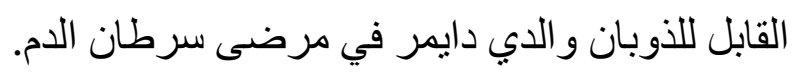

المرضى وطرق البحث: نم أخذ العينات من 40 مريضـا 2020 بعد مو افقتهم، وتم أخذ 40 عينـة من

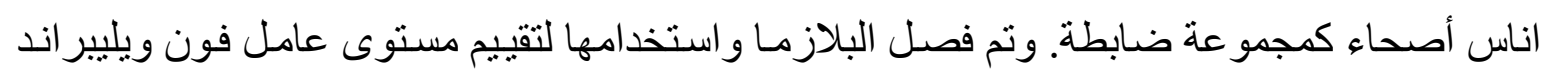

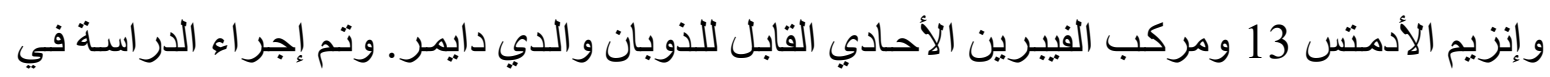
الفترة بين إبريل 2019 إلى مارس 13 ومركب 2020 بمستشفى سيد جلال الجامعي.

نتائج البحث: لوحظو وجود إختلاف ذو قيمة إحصائية بين المجموعات فيما يخصعامل فون ويليير اند و إنزيم الأدمتس 13 ومركب الفيبرين الأحادي القابل للذوبان و الدي دايمر ، وكانية وكانت النتائج طبيعية للمجمو عة الضابطة.

الاستتنتاج: يلعب عامـل فون ويليير اند و إنزيم الأدمتس 13 دور ا أساسيا في تكوين جعل مرضسى سرطان الدم عرضة للإصابة بالتجلطات. ويمكن استخدام مركب الفيبرين الأحادي القابل للذوبن الأبان كأداة



الكلمـات الدالـة: عامـل فونويليير اند، إنزيمـالأدمتس 13، مركب الفيبرين الأحسادي القابل للذوبان،

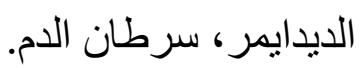

